\title{
Forum: stigma, discrimination and health: policies and research challenges. Postscript
}

\author{
Fórum: estigma, discriminação e saúde: \\ desafios políticos e acadêmicos. Posfácio
}

Francisco I. Bastos 1

\footnotetext{
1 Instituto de Comunicação

e Informação Científica

e Tecnológica em Saúde,

Fundação Oswaldo Cruz,

Rio de Janeiro, Brasil.

Correspondence

F. I. Bastos

Instituto de Comunicação

e Informação Científica

e Tecnológica em Saúde,

Fundação Oswaldo Cruz.

Av. Brasil 4365, Rio de

Janeiro, RJ 21045-900, Brasil.

francisco.inacio.bastos@hot-

mail.com
}

I wish to thank Simone Monteiro and Wilza V. Villela, the organizers of this Forum on discrimination, for the opportunity to comment on highly interesting and current studies in public health, in dialogue with various other fields, such as sociology, anthropology, political science, and philosophy, addressed so competently by the authors of the four articles on which I will now comment.

Monteiro et al. ${ }^{1}$ conduct an instigating review of Brazilian articles on discrimination, drawing on the SciELO bibliographic database (thus referring to Brazilian publications) and identify a scarcity of Brazilian research on the theme. Another conclusion by the authors is that the articles they reviewed focus primarily on individual experience of discrimination rather than a more structural and social approach to the issue.

In a second stage of the research under way by the two authors, it would be interesting if they analyzed both the research production by Brazilian authors in international journals (based on a literature search in databases such as PubMed/ MEDLINE, Scopus, and ISI-Web of Science) as well as the international literature in general, in order to respond to two questions that occurred to me while reading their paper 1 .

1) Have Brazilian authors published so little work on discrimination because of their limited personal interest, the gap between this issue and their own research agendas, or the limited receptiveness of editors and reviewers to articles on discrimination? Since there are no comprehensive registries of projects or initiatives that have not led to publications or that have generated few publications as compared to their initial objectives (as is commonplace with clinical trials), is it possible that such papers have not even been written, or if so, that they have not been well received by specialized public health journals in Brazil?

Systematic reviews and meta-analyses of findings from clinical trials clearly show that selective non-publication of so-called "negative" findings heavily influences the final conclusions on the efficacy and effectiveness of different procedures, e.g., the efficacy of certain drugs in various diseases 2. Obviously, such conclusions do not apply simplistically to articles that address themes that are closer to the social sciences, but they do call attention to possible gaps between the submission and actual publication of articles on the theme of discrimination, among others. Unfortunately, unlike the area of clinical trials in recent years, in which registration of trials is required by the funding agencies such as the $\mathrm{Na}$ tional Institutes of Health or the United Nations system agencies (the World Health Organization and its regional chapters, or UNAIDS), the only way to retrieve this information in other areas is to search for projects registered in the Lattes Curricula of the Brazilian researchers, which is not only toilsome, but can grossly underestimate the research projects, since such registration is 
up to the individual researchers, who may or may not register their projects (and they usually do not in the case of projects that fail to result in publications).

It would also be important to know whether Brazilian authors that publish on discrimination in international journals adhere to the dominant paradigms in international research on the theme, or whether they dialogue with the national specificities, for example, in the highly diverse approach to race and racism in the United States as compared to Brazil ${ }^{3}$.

2) A second dimension in this endeavor is to verify whether there is a paucity of research output on discrimination by Brazilian authors in international journals, or a more general scarcity of publications on the theme by all authors, regardless of nationality.

Although lacking a solid empirical basis, I would venture to say, in keeping with the discussion by Parker in his article for this Forum 4, that there has been a progressive depletion of a structural reading on public health interventions by the mainstream international public health research community in relation to various health problems, particularly striking in the field of HIV/ AIDS (analyzed by the authors), as a function of the undeniable predominance of preventive interventions of a biomedical nature, backed by the U.S. agenda for interventions in HIV/AIDS (see, for example, the research agenda of the HIV Prevention Trials Network - HPTN; http://www. hptn.org/index.htm), vigorously advocated by recent articles and editorials 5 .

It is thus pertinent to further analyze whether the characteristics of Brazilian research on discrimination, as indicated by the authors, correspond to the specificity of Brazilian output, the Brazilian research agenda, or the exhaustion of the theme at the international level, with indirect impacts on Brazilian research and publication.

The article by Carrara 6 addresses central issues in the contemporary debate on sexual rights in general and particularly the rights of minority groups subject to stigma and discrimination in Brazilian society. The author correctly includes these issues in both a broader conceptual agenda drawing on anthropology and philosophy, as well as referring to a set of initiatives for the protection and promotion of human rights and the struggle against violence, including pressing practical measures through legislative reforms, among others (e.g., measures taken in the school system and the media). Unfortunately, as highlighted by the author, the Brazilian Legislative Branch has proven lukewarm (if not outright negligent) towards these issues, contradicting a vigorous international trend that some American com- mentators (concerning the recent legalization of same-sex marriage in the State of New York) have compared to a new wave in the expansion of civil rights and freedoms, on the order of the profound legislative reform in the United States in the fight against racism and for women's full participation in all spheres of social life, especially relevant in the 1950s and 60s (available, respectively, at http://en.wikipedia.org/wiki/Same-sex_mar riage_in_New_York; http://en.wikipedia.org/ wiki/AfricanAmerican_Civil_Rights_Movement_ (1955\%E2\%80\%931968; and http://en.wikipedia. org/wiki/Second-wave_feminism).

Unlike the United States, where the issue has received wide attention in Congress, in Brazil the rare legislative measures for change have faced a barrage of criticism and manifestations of intolerance within the National Congress itself, while the Brazilian Supreme Court has taken a proactive role on the issue, as mentioned by the author, as well as in relation to freedom of expression towards the use of illegal drugs, especially marijuana, another issue avoided by the Brazil Congress.

Bastos \& Faerstein 7 document the conceptual changes and new perspectives in terms of the design of studies and criteria for measuring discrimination. I wish to highlight two points that I consider particularly valid, although incomplete, in the authors' article.

First, I do not believe that the contribution by social psychology to the understanding of discrimination looms over that of anthropology and sociology, as reviewed in detail by Parker in his article for this Forum 4; rather, that social psychology's approach to the issue is closer to the conceptual and methodological paradigm of epidemiology and thus proves more applicable to studies and debates by the latter. Due to the widespread influence of functionalism on both North American social psychology and contemporary social epidemiology, it has become a common theoretical reference for both fields. Authors that adhere to other conceptual traditions, like Paul Farmer, the American physician and anthropologist, as highlighted by Parker 4, have substantially enriched the contemporary debate in public health, although curiously Farmer (like other similar authors) has a limited presence in the current epidemiological debate, even though he is highly influential in public policymaking and in the practical implementation of clinical care programs for HIV and tuberculosis 8 . In the specific case of Paul Farmer, we could argue that the author is both an anthropologist and an infectious diseases expert and clinician, with no systematic work in the field of epidemiology. In a broader sense, one could highlight the difficulty 
in elaborating scales and measuring independent (or supposedly independent) variables outside the context of a paradigm that fractions social reality into discrete and measurable elements. As far as we know, the contemporary alternative that allows full integration between a non-functionalist reading of social reality and the epidemiological method is the contemporary social networks theory, but even here the most substantial contributions have been proposed by mathematical sociologists 9 and physicists 10 as well as by what unfortunately is still a limited number of epidemiologists 11 , except for the numerous articles on the spread of pathogens through transmission networks (see review in Codeço \& Coelho ${ }^{12}$ ).

Contemporary epidemiology faces a second obstacle, currently insurmountable, mentioned by Bastos \& Faerstein 7, although not explicitly for this purpose. The difficulty has been taken for granted to such an extent that it has not even been viewed as an issue to be approached by the field. I mention here the persistent and prevailing Cartesian approach in epidemiology since the field's beginning, in its interface with clinical medicine and so-called psychosomatic medicine. Contrary to modern concepts in the neurosciences, epidemiology continues to distinguish what the authors, as all the other epidemiological articles of which I am aware, refer to as "direct effect, leading to the manifestation of adverse mental health conditions" 7 (p. 179) and "the pathological effects of discrimination [...] mediated by psycho-physiological alterations" 7 (p. 179). According to the contemporary neurosci-

\section{References}

1. Monteiro S, Vilella WV, Knauth D. Discrimination, stigma, and AIDS: a review of academic literature produced in Brazil (2005-2010). Cad Saúde Pública 2012; 28:170-6.

2. Chan AW, Hróbjartsson A, Haahr MT, Gøtzsche PC, Altman DG. Empirical evidence for selective reporting of outcomes in randomized trials: comparison of protocols to published articles. JAMA 2004; 291:2457-65.

3. Telles EE. Race in another America: the significance of skin color in Brazil. Princeton: Princeton University Press; 2006.

4. Parker R. Stigma, prejudice and discrimination in global public health. Cad Saúde Pública 2012; 28:164-9. ences, drawing not only on Descartes, but also on his critic Baruch Spinoza, the effects described in items 1 and 2 constitute one and the same thing, i.e., the ways of living and expressing the bodymind whole (see the detailed analysis anchored in the contemporary neurosciences and in the philosophy of Spinoza, Damasio 13).

Thus, when dealing with the issue of stigma, discrimination, and prejudice, all of us public health researchers need to deal with our own set of preconceived ideas, whether pertaining to an inability to incorporate less fragmented visions of living in society, or to our incapacity to transform ideas that circulate widely in society into concrete facts (even while we find it odd to encounter apathy and hostility in the Brazilian Congress towards ideas from a society it claims to represent), or even the exclusively biomedical "preventionism" that has gained increasing ground in various areas of public health, as exemplified by current interventions in HIV/AIDS, but equally present in various other areas, as in the massive prescription of antidepressant drugs rather than more comprehensive lifestyle changes such as healthier diets and regular physical exercise 14 .

In short, the on-going effort to reduce harm and suffering imposed on others on grounds of prejudice, stigma, and discrimination remind us once again of the wisdom of Spinoza, when he states in an autobiographical passage that " $I$ have made a ceaseless effort not to ridicule, not to bewail, not to scorn human actions, but to understand them".
5. Underhill K, Operario D, Skeer M, Mimiaga M, Mayer K. Packaging PrEP to prevent HIV: an integrated framework to plan for pre-exposure prophylaxis implementation in clinical practice. J Acquir Immune Defic Syndr 2010; 55:8-13.

6. Carrara S. Discrimination, policies, and sexual rights in Brazil. Cad Saúde Pública 2012; 28:184-9.

7. Bastos JL, Faerstein E. Conceptual and methodological aspects of relations between discrimination and health epidemiological studies. Cad Saúde Pública 2012; 28:177-83.

8. Furin JJ, Behforouz HL, Shin SS, Mukherjee JS Bayona J, Farmer PE, et al. Expanding global HIV treatment: case studies from the field. Ann N Y Acad Sci 2008; 1136:12-20. 
9. Salganik MJ, Dodds PS, Watts DJ. Experimental study of inequality and unpredictability in an artificial cultural market. Science 2006; 311:854-6.

10. Porter MA, Mucha PJ, Newman ME, Warmbrand CM. A network analysis of committees in the U.S. House of Representatives. Proc Natl Acad Sci USA 2005; 102:7057-62.

11. Christakis NA, Fowler JH. The spread of obesity in a large social network over 32 years. N Engl J Med 2007; 357:370-9.

12. Codeço CT, Coelho FC. Redes: um olhar sistêmico para a epidemiologia de doenças transmissíveis. Ciênc Saúde Coletiva 2008; 13:1767-74.
13. Damasio A. Looking for Spinoza: joy, sorrow, and the feeling brain. Orlando: Harcourt; 2003.

14. Fabricatore AN, Wadden TA, Higginbotham AJ, Faulconbridge LF, Nguyen AM, Heymsfield SB, et al. Intentional weight loss and changes in symptoms of depression: a systematic review and metaanalysis. Int J Obes (Lond) 2011; [Epub ahead of print].

Submitted on $11 / \mathrm{Jul} / 2011$

Approved on 04/Aug/2011 